\section{THE GENERAL HOSPITALS AND THE TRAINING OF MIDWIVES.}

\section{To the Editor of THE LANCET.}

SIR,-In commenting on the report of a meeting recently convened by the Association for Promoting the Training and Supply of Midwives, the Times in a leading article expressed regret that none of the speakers, beyond urging the necessity for increased support of the Association, gave any indication as to the means by which the serious difficulty is to be met which may arise in 1910 when the clauses in the Act forbidding the practice of midwifery by unqualified persons come into operation. The opinion was also expressed that "a very definite organisation with definite and clearly stated aims is a necessary condition of any extended support from the public." A subsequent letter from the Council of the Association makes the issue clear-viz, which is to come first, the plan or the money?

I am writing in the hope that the suggestions contained in this letter may help the Association to a decision upon this point. I cannot clain to speak with any authority on the general question, but I have been led during the past two years to take an interest in it owing to my appointment as a visitor of some of the lying-in hospitals of London by the Council of King Edward's Hospital Fund. No one can enter the wards of one of these hospitals without being struck with the enormous advantage which any poor woman whose labour is conducted there enjoys over her less fortunate sister who is confined in her own home, often amidst surroundings which can only be realised by those who have actually witnessed them. It is gratifying to learn that by the adoption of a rigidly aseptic and antiseptic method maternal mortality has in these institutions been practically abolished. It is equally saddening to reflect that whilst the lying.in ward has been transformed from a death-trap to a place of the greatest attainable safety, there has been little or no diminution in the mortality from child-birth throughout the country generally.

The Faculty of Medicine of the University of London was recently asked by the Senate to advise as to the action to be taken by the University upon the proposed regulation of the General Medical Council that every student shall be required to have received instruction and gained his practical knowledge of midwifery by attending the requisite number of labours, either in a lying-in hospital or in the lying-in ward of a general hospital. I am glad to say that a resolution was passed that in the opinion of those present " teaching in practical midwifery in the wards of a lying-in hospital or in the lying-in ward of a general hospital should be made compulsory as soon as practicable."

I lately suggested to the Weekly Board of the Middlesex Hospital that a lying-in ward should be established, so that our students may learn this most important branch of their profession under the best possible concitions and not, as hitherto, by attendance upon the poor living in the area supplied by the hospital. The suggestion received the approval of the board and of the medical staff and a committee is about to report upon the changes necessary to carry it into effect. The existence of such a ward is no new thing, as in 1747 it was enacted that "a third part of the beds used in the hospital from time to time be appropriated to the use of lying-in women." The total number of beds in the hospital at that date was either 18 or 22 . In 1749 a rule was established that "whenever there shall be an increase of beds for sick and lame the same number be also added for lying-in women." In 1783, owing to lack of funds, retrenchments became necessary and these were continued at intervals until 1807, when the lying-in ward was abolished.

Such a ward in a general hospital to which a medical school is attached would serve a fourfold purpose: 1 . It would insure that a certain number of poor women were delivered under conditions involving in a normal pregnancy the minimum risk to life. 2. The offspring would be free from the danger of contracting purulent ophthalmia, which two of the speakers at the meeting referred to stated to be the cause of fully one-fourth of the cases of blindness in the community to-day. 3. It would afford the students an opportunity of learning thoroughly the aseptic and antiseptic technique of modern midwifery, knowledge which must in their future practice be of the greatest service to them and therefore to the public. 4. It would allow the hospital to become a centre for the training of nurses skilled and certificated in midwifery and thus increase its claims to public support. Some of these nurses might be available for attendance upon the poor living in the neighbourhood of the hospital, thus replacing the services of the students.

I would therefore suggest to the Association that it should forthwith institute a campaign throughout the country to urge: 1. That every general hospital should as soon as possible provide a lying-in ward. 2. That the general hospitals in each county should become centres for the instruction of midwives, who would obtain there the certificates necessary to secure admission to the Roll. 3. That one or more branches of the association should be established in each county in connexion with the general hospitals in order to ascertain and provide for the wants of the county as regards midwives and to organise and to supervise their work. 4. That the county councils and local authorities should exercise the powers given to them by the Act of making grants towards the cost of the education given to midwives in the hospitals; thus the whole community would bear a part of the expense to which the hospitals would be put in carrying this proposal into effect and not only those members of it who recognise their duties to the poor.

I venture to submit these suggestions as the basis of a scheme which may provide "the definite organisation with clearly stated aims" necessary to secure increased public support of the Association. I have not referred to the good work which I know Queen Charlotte's Lying in Hospital is doing in increasing the provision for the instruction of students, as the need is for a scheme applicable to the country as a whole.

I am, Sir, yours faithfully, J. K. FOWLER,

Dean of the Faculty of Medicine, University of London. Clarges-street, W., Dec. 28th, 1907.

\section{THE COEFFICIENT OF DISINFECTANTS AS REGARDS THE PLAGUE BACILLUS.}

To the Editor of THE LANCET.

SIR, - The statements made with reference to the coefficient of various disinfectants against the bacillus pestis indicate that this organism is particularly susceptible to the influence of the various preparations used for disinfecting purposes, but I gravely doubt whether all these statements are absolutely reliable. My reason for saying this is based upon the results of a series of experiments made when examining a well-known disinfectant. I found that using broth for cultivating purposes, with and without the addition of a little butter, the results were sometimes doubtful. I therefore made from all the tubes giving no definite indications of growth agar slope cultures and was not surprised to find after several days that a distinct growth of the bacillus pestis made its appearance. The result was that the disinfectant under trial gave a coefficien't about the same as that obtained when the bacillus typhosus was used, whereas judging from the broth cultures alone it was nearly twice as high. An attempt was made to use agar slopes in the first instance instead of the broth, but the results then differed widely from those obtained either with broth alone or with broth followed by agar. Probably other bacteriologists interested in this subject may care to repeat my experiments and confirm or disprove my results. This is my excuse for tronbling you with this letter.

I am, Sir, yours faithfully, JOHN C. THRESH, M.D. Vict., \&c.

London Hospital Medical College, Dec. 23rd, 1907.

\section{TWINS : A CURIOUS INCIDENT.}

\section{To the Editor of THE LANCET.}

SIR,-At Stoke Newington recently inquests were held upon the bodies of twin boys, aged 18 months, who were found dead at the same time in the same bed on a Friday afternoon about 6 P.M. One child had been brought up by the bottle on cow's milk and barley water and the other had been suckled. Both had seemed well until the Sunday before, when both became poorly with colds in the head and conghs. The mother treated the children with castor-oil and embrocations of camphorated oil. She did not think either was seriously ill until the Friday, when one was taken to a doctor who prescribed for it at noon; the other had no medical attendance. The parents declared that both had 
been seen alive by them about 5.30 P.M. ; half an hour after both were dead, lying on their sides, faces not covered up, some distance apart. Post-mortem examinations showed a similar state of broncho-pneumonia; there were no injuries and no suspicion of foul play.

$$
\text { I am, Sir, yours faithfully, }
$$

W. W. WESTCOTT

Dec. 28th, 1907.

Coroner.

\section{LONDON'S MILK-SUPPLY.}

\section{To the Editor of THE LANCET.}

SIR,-I notice in THE LANCET of Dec. 21st, 1907, p. 1778, that a reference is made to the adoption of new regulations by the Hailsham rural district council under the Dairies, Cowsheds, and Milkshops Orders 1885, 1886, and 1899. In the same article you imply that the Hailsham council has had no Dairy, Onwshed, and Milkshop Regulations for the past 20 years. You have evidently been misinformed. As a fact the Hailsham rural district council was one of the first councils to make regulations undar the Dairies, Cowsheds, and Milkshops Orders 1885, 1886, and the old regulations were more strict than the new regulations. The Hailsham council, acting on the advice of its medical officer of health, has recently brought the above regulations up to date and these remodelled regulations will come into force on Jan. 1st, 1908. It is no doubt these revised regulations that your correspondent has mistaken for the Order. I would point out that the Dairies, Cowsheds, and Milkshops Order is not adoptive as described in your article under London's Milk-supply.

I would also draw your attention to the fact that the Order does not compel local authorities to make regulations but, unfortunately, merely empowers them to do so, and the Legislature should doubtless have made the making regulations under the Order compulsory instead of permissive. It is a matter for deep regret that your usually accurate journal should be blemished by a contribution the author of which shows want of knowledge, both as to his legal principles and facts.

$\overline{1}$ am, Sir, your obedient servant,

Hugh STOTT,

Dec. 26th, 1907. Medical Officer of Health, \#ast Sussex Combined

** We are sorry to find that our correspondent has made a mistake.-ED. L.

\section{MEDICAL PRACTICE IN TURKEY.}

\section{To the Editor of THE LANCET.}

SIR,-Perhaps it may interest a few of your readers to know how the licence to practise medicine in the Turkish Empire is to be obtained. Perhaps this licence is not absolutely necessary for an English practitioner whose work lies solely in an Kaglish institution, yet it is strongly recommended to be obtained as without it one has no legal right to practise.

First from the Consulate (fee 10s.), or from some friend who can write a formal Turkish letter, a "petition" is obtained stating that $\mathrm{X}$, a British subject, graduate of such a University, desires the licence of the Ottoman Government. This letter addressed to the Director-General of Medical Affairs (Nāzir Mekteb Tibbiyé St $\bar{a}^{h} \bar{a} \cdot \hat{e}$ ) you take to the Haidar Pasha new military medical school near Skutari, to a room called evraq odasy. There a clerk gives you a form bearing a number (fee 20 paras $=1 d$.), and you are probably told to call in a week's time. Meanwhile, the petition goes before some authority and on your next visit you pay in an adjoining office (Bureau de Comptabilité) $£$ T. $20+20$ paras; no receipt is given jet. Five days later, probably, on visiting the original office and displaying the number, the clerk, turning up his register, writes "council" on your form, and after waiting an hour or so you enter to see the council which examines your university diploma and medical registration estifiate. The former it retains, all things being satisfactory, aud you enter an adjoining room for a $v$ vîa $v o c e$ examination by the professor of anatomy, of surgery, and of medicine. This examination is a perfectly fair gentlemanly one. If you display a reasonable knowledge of your profession you are immediately afterwards invited to the council-room where the chairman declares your acceptance.

The examination must be taken in French or Turkish. An interpreter is allowable. Then comes a wait of some ten days during which your diploma and the result of the test, \&c., pass to the Director-General and are finally returned to the school. It is necessary in the meantime to pay a visit to the Sublime Porte to have your passport legalised (fee half Turkish pound +2 piastres). The return of your papers is announced in Turkish on a notice board in the ball in which you do so much waiting. Your university diploma is now returned to you and also a receipt for the fee, and after a period varying according to whether there are others ready with you or not, you are led before the DirectorGeneral to swear the oath not to procure abortion, not to treat hardly the poor, to call your professional brethren in consultation when necessary, \&c., and after paying 21 piastres $(3 s .6 d$.) for a stamp, your licence is handed to you The examination and council, \&x., are held three times weekly-Mondays, Thursdays, and Saturdays, and it is advisable to call regularly on each of these days when waiting, as the clerk's instruction to come in a week's time is but a way of speaking. In the first office and the feepaying office there is no one who speaks French. The whole affair takes three weeks if very fortunate, five weeks $u$,ually, and seven weeks if unfortunate. In Egypt the same affair takes from four to five days and there is no examination and a nominal fee of $3 s .6 d$. or so to pay.

I am, Sir, yours faithfully,
Baghdad.
P. A. H. RADClifFe, M.B. Vict., D.T.M.

\section{THE TREATMENT OF PUERPERAL SE'PSIS.}

\section{To the Editor of THE LANCET.}

SiR,-In a letter in THe LANCET of Dec. 2Lst, 1907, p. 1785, Dr. Amand Routh says, "I cannot recall any acute septic condition of the endometrium where curettage with a sharp curette has done good." I should like to bring forward some statistical evidence on this point. In the Journal of Obstetrios for January, 1907, in a paper dealing with the treatment of puerperal sepsis, I wrote: "Out of 79 cases (of my own) treated by general means, with or without intra-uterine douches, 37 died-a mortality of 46 per cent. In 86 cases where the method I have described was employed the mortality was 23 per cent. only." I can. now add to the latter serits 43 more cases with 11 deaths. The method referred to consists in the removal of the endometrium as completely as possible with a large sharp curette followed by swabbing of the resulting raw surface with undiluted izal. I should add that all the patients were intensely ill when I first saw them and that the large majority had been treated previously by intra-uterine and vaginal douches for several days, the average day of admission to hospital being, in fact, the fifth of the prrexial period or, in other words, the stage which is cersainly not the most favourable for the use of the sharp curette. I do not see mild or early cases at all.

I am well aware of the fallacies which attend the nse of the statistical method in such a complex disease as puerperal sepsis, but I think it is evident that these figures do not justify the inference that the use of the sharp curette is per $s e$ either dangerous or inadvisable and that the number of cases, 208 in all, is sufficiently great to be worth quoting in. this connexion. I am, Sir, yours faithfully, A. KNYVETT GORDON.

Monsall Hospital, Newton Heath, Manchester, Dec. 22nd, 1957.

\section{NOTIFICATION OF BIRTHS ACT.}

\section{To the Editor of THE LANCET.}

SiR, - The town council here has adopted the above Act. and I shall be compelled under a penalty to notify all my confinement cases without receiving any compensation therefor, which is not quite just. However, the spirit of the Act is a step in the right direction and one must not complain. It seems a pity that the scope of the Act did not enable the local authorities to take an interest in both the mother and the child at parturition. Obstetricians who have the true spirit of their office must have felt unhappy and uncomfortable after refusing to get out of bed to attend a woman in labour who had been so improvident as not to have engaged anyone to attend her, knowing well from past experience that the only recompense that these improvtdent prople afford is the approving conscience of having done your duty, which is very satisfying at the time, but of no avail in paying the bills of the butcher, 